OPEN ACCESS

Edited by:

Janardhan Y. C. Reddy,

National Institute of Mental Health and

Neurosciences (NIMHANS), India

Reviewed by:

Michael Grady Wheaton,

Columbia University, United States

Brian P. Brennan,

Massachusetts General Hospital and

Harvard Medical School,

United States

${ }^{*}$ Correspondence:

Karin C. P. Remmerswaal

k.remmerswaal@ggzingeest.nl

tThese authors have contributed equally to this work and share first authorship

Specialty section

This article was submitted to Mood and Anxiety Disorders, a section of the journal Frontiers in Psychiatry

Received: 27 January 2021 Accepted: 11 March 2021

Published: 12 April 2021

Citation:

du Mortier JAM, Remmerswaal KCP Batelaan NM, Visser HAD, Twisk JWR, van Oppen $P$ and van Balkom AJLM (2021) Predictors of Intensive

Treatment in Patients With

Obsessive-Compulsive Disorder. Front. Psychiatry 12:659401. doi: 10.3389/fpsyt.2021.659401

\section{Predictors of Intensive Treatment in Patients With Obsessive-Compulsive Disorder}

\author{
Johanna A. M. du Mortier ${ }^{1 \dagger}$, Karin C. P. Remmerswaal ${ }^{2 \star t}$, Neeltje M. Batelaan ${ }^{2}$, \\ Henny A. D. Visser ${ }^{1}$, Jos W. R. Twisk ${ }^{3}$, Patricia van Oppen ${ }^{2}$ and Anton J. L. M. van Balkom ${ }^{2}$ \\ ${ }^{1} \mathrm{GGz}$ Centraal, Innova, Amersfoort, Netherlands, ${ }^{2}$ Amsterdam UMC, Vrije Universiteit, Department of Psychiatry, Amsterdam \\ Public Health Institute and GGZ inGeest Specialized Mental Health Care, Amsterdam, Netherlands, ${ }^{3}$ Amsterdam UMC, Vrije \\ Universiteit, Epidemiology and Biostatistics, Amsterdam, Netherlands
}

Background: Few studies have investigated which patients with obsessive-compulsive disorder (OCD) do not recover through regular cognitive behavior therapy or pharmacotherapy and subsequently end up in intensive treatment like day treatment or inpatient treatment. Knowing the predictors of intensive treatment in these patients is significant because it could prevent intensive treatment. This study has identified predictors of intensive treatment in patients with OCD.

Methods: Using 6-year longitudinal data of the Netherlands Obsessive Compulsive Disorder Association (NOCDA), potential predictors of intensive treatment were assessed in patients with OCD $(n=419)$. Intensive treatment was assessed using the Treatment Inventory Costs in Patients with Psychiatric Disorders (TIC-P). Examined potential predictors were: sociodemographics, and clinical and psychosocial characteristics. Logistic Generalized Estimating Equations was used to estimate to what extent the various characteristics (at baseline, 2- and 4-year assessment) predicted intensive treatment in the following 2 years, averaged over the three assessment periods.

Results: Being single, more severe comorbid depression, use of psychotropic medication, and a low quality of life predicted intensive treatment in the following 2 years.

Conclusions: Therapists should be aware that patients with OCD who are single, who have more severe comorbid depression, who use psychotropic medication, and who have a low quality of life or a drop in quality of life are at risk for intensive treatment. Intensive treatment might be prevented by focusing regular treatment not only on OCD symptoms but also on comorbid depression and on quality of life. Intensive treatment might be improved by providing extra support in treatment or by adjusting treatment to impairments due to comorbid depressive symptoms or a low quality of life.

Keywords: obsessive-compulsive disorder, OCD, intensive treatment, longitudinal, quality of life, psychotropic medication, comorbid depression 


\section{INTRODUCTION}

Obsessive-compulsive disorder (OCD) is an impairing disorder, often with a chronic course (1). There are evidence-based treatments for OCD, namely cognitive behavior therapy (CBT) and psychotropic medication, that can be offered in more or less intensive formats (2). Multidisciplinary guidelines recommend determining the designated intensity of treatment according to the principles of so-called "stepped care" (3-5). In line with stepped care, the least intensive treatment possible is delivered to patients first, taking into account the nature and course of their symptoms. In the case of non-response, treatment may be "stepped up" to a more intensive level in an effort to meet the treatment goals (6). In the National Institute for Health and Care Excellence (NICE) guideline, the first step in the treatment of OCD consists of awareness, recognition and assessment (3). Next step strategies comprise of CBT, antidepressant medication, or a combination of these. In the case of non-response, treatment is stepped up to treatment by a multidisciplinary team with expertise in the management of OCD. Intensive treatment such as day treatment or inpatient treatment may be considered in this latter step for the most severe, impaired, and treatmentresistant patients. In the Netherlands, intensive treatment usually consists of multimodal treatment, with CBT being the main therapy, offered in a group with other patients with anxiety disorders and OCD. It can be offered in a day-care setting or in an inpatient setting. Intensive treatment usually takes several (parts of) days a week up to 5 days a week for a few months to 1 year. Admission may also be necessary when patients are in crisis.

Up till now, no longitudinal studies into the predicting factors of intensive treatment in OCD have been published. However, cross-sectional research exists, describing the characteristics of patients with OCD in intensive residential treatment. These patients were treatment-resistant to antidepressants and/or CBT, suffered from severe OCD symptoms and psychiatric comorbidity (7-9), had an early age of onset of OCD and a long duration of the disorder $(10,11)$, often did not have a partner or a job (10-12) and had a low quality of life, with scores of one to two standard deviations below the general population (13-17).

In populations with other mental disorders, more is known about predictors of hospitalization. A systematic review of 58 papers on predictors of readmission in patients with several mental disorders indicates that previous hospitalization, younger age, being unmarried, having lower financial means, not being satisfied with the index treatment, having more hospital days on the index admission, and a negative attitude toward medication were predicting factors for psychiatric readmission (18). In addition, being male, having psychotic symptoms, a longer duration of untreated psychosis, less social satisfaction, disturbed family dynamics, residing in an urban area, and illegal drugs misuse were found predictive of hospitalization in recent prospective cohort studies involving several mental disorders (18-22). A population study combined several survey and register databases of 2,638 individuals born in 1953, including interviews with their mothers. From this study it appeared that poor family relations in adolescence were associated with an increased risk of inpatient psychiatric treatment in the years 1969 until 2008 (20).

Knowledge of characteristics that predict future intensive treatment might help to optimize first steps of treatment for patients with OCD to prevent the need for intensive treatment. This is significant because intensive treatment may contribute to stigmatization and the disruption of the lives of patients by hindering work, education, care for children, hobbies or social contacts $(23,24)$. In addition, intensive treatment is expensive, which burdens society with costs. Nevertheless, intensive treatment is still the best available treatment for the most severe and impaired patients with OCD. Another significance of predictors of intensive treatment is that they might be used to improve intensive treatment by tailoring it to the characteristics of the patients who need it.

The goal of the present study was to identify predictors of starting with intensive treatment. In the rest of the text, we will refer to this as "predictors of intensive treatment," for reasons of readability. We have selected potential predictors based on the above presented research findings in other populations. In addition, potential predictors were selected that have been associated with course and severity of OCD, leading to the following potential predictors: sociodemographic variables, clinical variables, and psychosocial variables including personality traits $(25,26)$, the quality of the social network (27), and childhood trauma (28-30). We hypothesized that being male, being younger, having more severe symptoms, poor insight in OCD, childhood trauma and a lower quality of social relationships are predictors of intensive treatment.

\section{METHODS}

The reporting of this study conforms to the STROBE statement (www.strobe-statement.org).

\section{Procedure}

Data were derived from the Netherlands Obsessive Compulsive Disorder Association (NOCDA) study, longitudinal cohort study investigating the naturalistic long-term course of OCD in patients referred to mental health care centers. The NOCDA study design and baseline characteristics of the study sample are described in detail elsewhere (31). The NOCDA study was accredited by the Medical Ethical Committee of the VUUniversity Medical Center in 2005.

After their clinical assessment at one of the contributing mental health clinics, 687 patients aged 18 years and over with a lifetime diagnosis of $\mathrm{OCD}$, as determined by the administration of the Structured Clinical Interview for DSM-IV Axis I Disorders (SCID-I) (32), were asked to participate in the NOCDA study. Since NOCDA aims to follow a large representative sample of OCD subjects in different stages of the disease and with different degrees of illness severity, the only exclusion criterion was an inadequate understanding of the Dutch language for the purposes of the completion of interviews and self-report questionnaires. Comprehensive measurements were done at baseline and after 2, 4 , and 6 years. 
Of the 687 patients who were asked to participate in the NOCDA study, 419 (60.9\%) gave written informed consent and were enrolled in the study. A comparison on basic demographic characteristics between patients that $\operatorname{did}(n=419)$ and did not $(n$ $=268$ ) agree to participate yielded no significant differences.

Baseline measurements took place between 2005 and 2009 and included validated semi-structured interviews and selfreport questionnaires to gather information on a broad range of variables related to OCD, comorbidity, and psychosocial consequences. The baseline assessment took about $5 \mathrm{~h}$. All included participants were contacted after 2, 4, and 6 years for assessment, irrespective of their treatment status. The follow-up assessments took about $3 \mathrm{~h}$ and in most cases (80\%) they were performed by the same research assistant. During the follow-up period, participants received treatment as usual. Three hundred and eleven patients participated in the 2-year assessment (total dropout 26\%), 295 patients in the 4-year assessment (total dropout $30 \%$ ), and 272 patients in the 6-year assessment (total dropout $35 \%$ ).

\section{Primary Outcome Measure: TIC-P}

Treatment intensity was derived from the Treatment Inventory of Costs in Patients with mental disorders (TIC-P) (33). This is a 15 -item interview assessing health care consumption in the previous 6 months (at baseline) or since the previous interview (at 2-, 4-, and 6-year). Treatment was scored as "intensive" when patients responded on the TIC-P interview (33) by stating that they were receiving day-care treatment or inpatient treatment in a psychiatric hospital or a specialized OCD clinic. In all other cases, treatment was scored as "not intensive."

\section{Potential Predictors of Intensive Treatment in Patients With OCD}

We studied three categories of potential predictors: sociodemographic, clinical, and psychosocial characteristics.

\section{Sociodemographic Characteristics}

Age (in years), gender, having a partner (yes, no), having children (yes, no), independent living situation [yes (living alone, with partner or children), no (living in a mental health institution or with parents)], education (number of years), paid employment (yes, no), and income (16 categories of increasing income).

\section{Clinical Characteristics}

Severity of OCD was assessed using the Yale Brown Obsessive Compulsive Scale for Severity (Y-BOCS) $(34,35)$. Age of onset of OCD was assessed using the SCID-I as the earliest age at which patients fulfilled the criteria for OCD. In order to assess the number of current comorbid mental disorders, the ascertained diagnoses on the SCID-I were counted (anxiety, mood-, post-traumatic stress-, eating-, somatoform-, and substance-related disorders, and psychotic disorders). Presence and severity of comorbid anxiety symptoms were assessed using the Beck Anxiety Inventory (BAI) (36), while comorbid depressive symptoms were measured using the Beck Depression Inventory (BDI) (37-39). Psychotropic medication was assessed using the TIC-P (33), measuring use of all types of psychotropic medication in the previous 6 months (at baseline and follow-up). Insight in OCD was measured using the Overvalued Ideas Scale (OVIS) (40).

\section{Psychosocial Characteristics}

Childhood trauma was assessed using the Structured Trauma Interview (STI) (41). Traumas on the STI are: (1) early separation from parent; (2) and (3) parental dysfunction of mother or father respectively; (4) witnessing of interparental violence; (5) physical abuse; (6) sexual abuse. Ascertained childhood traumas were summed. Personality characteristics according to the Big Five were assessed using the Five-Factor Personality Inventory (FFPI) (42). Subscales of the FFPI are: extraversion, agreeableness, conscientiousness, emotional stability, and autonomy. Social support was assessed using the Social Support Inventory (43). The self-rated EuroQol five dimensional questionnaire (EQ-5D) was used to assess quality of life (44). The EQ-5D contains five dimensions significant for quality of life: mobility, selfcare, daily activities, pain/discomfort, and depression/anxiety.

Stable characteristics like age, gender, age of onset OCD, childhood trauma, and personality characteristics were assessed at baseline only. Characteristics that could vary over time were assessed at baseline, 2- and 4-year assessment. These characteristics were: relationship status, children, living situation, education, employment, severity of OCD, number of current comorbid mental disorders, comorbid anxiety and depressive symptoms, use of psychotropic medication, social support, and quality of life. An exception is the characteristic insight in OCD, which was assessed at 2- and 4-year assessment.

\section{Quality Aspects of NOCDA}

The NOCDA study was coordinated by the Department of Psychiatry at the Amsterdam UMC/GGZ inGeest, Amsterdam, and included seven sites that were specialized OCD mental health clinics spread over the Netherlands. All research assistants had extensive experience in assessing OCD. In addition, they received a 2-day course, and regular follow-up 1-day training sessions in which videos of the SCID were rated, assessor rating scales were practiced, and questions and problems raised by the research assistants were able to be addressed. The first two interviews of all research assistants were audiotaped and monitored by the fieldwork coordinator in order to address any misunderstandings or errors in performing the measurements. All subsequent interviews were audiotaped for future reference. The audiotapes were continuously randomly monitored in about $10 \%$ of all taped interviews, as well as on the basis of questions raised by the research assistants and the fieldwork coordinator. Assessments were done by around 30 research assistants (profession: psychologist or experienced research nursing staff).

\section{Statistical Analyses}

Logistic Generalized Estimating Equations (GEE) with an exchangeable correlation structure was used to estimate to what extent the various characteristics (at baseline, 2- and 4year assessment) predicted intensive treatment in the following 


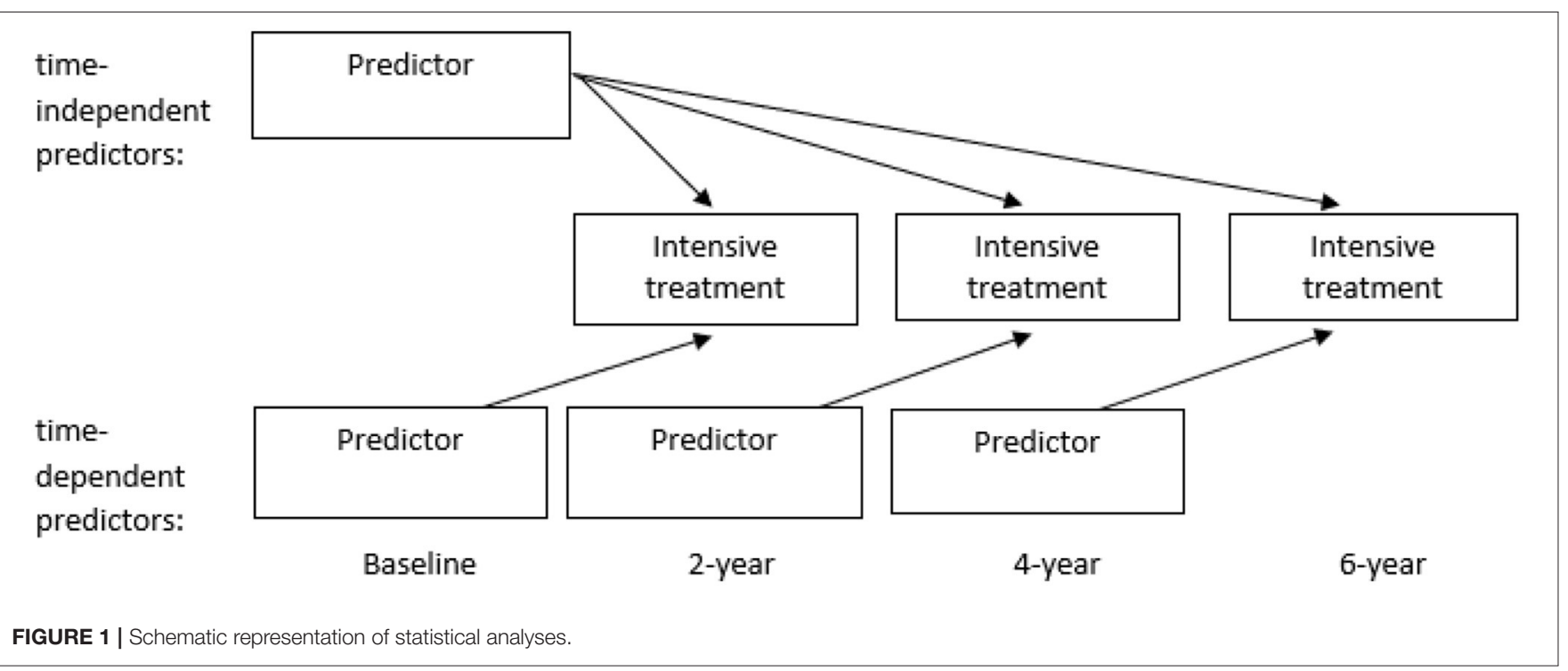

period of 2 years, averaged over the three assessment periods (see Figure 1).

The following GEE analyses were performed: (1) univariable analyses in which all potential predictors were analyzed separately; (2) multivariable analyses within the three categories of potential predictors in which all variables of a category showing statistical significance in the univariable analyses were analyzed together; and (3) a multivariable analysis over the three categories including all variables showing statistical significance $(p<0.05)$ in the multivariable analyses within the three categories of potential predictors. A backward selection strategy was used to obtain the final multivariable models.

As a sensitivity analysis, we repeated the analyses but corrected for Y-BOCS severity. Insight in OCD will be analyzed separately using the other characteristics because it was assessed at 2- and 4-year assessment only.

\section{RESULTS}

\section{Description of Potential Predictors of Intensive Treatment}

Table 1 presents the description of the potential predictors at baseline, 2- and 4-year measurement that may predict whether patients will receive intensive treatment in the following 2 years. The mean severity of OCD and comorbid symptoms decreased from baseline to 2-year measurement. From 2- to 4year measurement, these severity scores stabilized or increased slightly.

\section{Description of 6-Year Course of Intensive Treatment}

Table 2 presents the description of the intensive treatment variable over the course of 6 years. Over time, fewer patients were treated in mental health care (outpatient care as well as intensive treatment).

\section{GEE Regression Analyses: Potential Predictors of Intensive Treatment}

Table 3 presents the results of the analyses of the potential predictors of intensive treatment 2 years later over a time period of 6 years.

In the univariable analyses, not having a partner, a dependent living situation, fewer years of education, not having a paid job, more severe OCD, more current comorbid diagnoses, more severe comorbid anxiety and depression, use of psychotropic medication, less extraversion, less autonomy, less social support, and a lower quality of life all significantly predicted intensive treatment 2 years later.

In the multivariable analysis of the sociodemographic variables, not having a partner and not having a paid job significantly predicted intensive treatment 2 years later. Predictors in the multivariable analysis of the clinical variables were more severe comorbid depression and use of psychotropic medication, while in the multivariable analysis of the psychosocial variables a lower quality of life predicted intensive treatment 2 years later.

For the final multivariable model, in which all significant predictors from the previous multivariable models were analyzed together, severity of comorbid depression and quality of life could not be included together due to high collinearity. Because severity of comorbid depression had a stronger association with intensive treatment, a final multivariable model was made with this variable and quality of life was not included (Table 3 model 1). In this model, not having a partner, more severe comorbid depression and use of psychotropic medication significantly predicted intensive treatment 2 years later. When quality of life was substituted for severity of comorbid depression in the final multivariable model (Table 3 model 2), it appeared that a lower quality of life significantly predicted intensive treatment 2 years later as well as not having a partner and use of psychotropic medication. 
TABLE 1 | Descriptives of potential predictors of IT in patients with OCD.

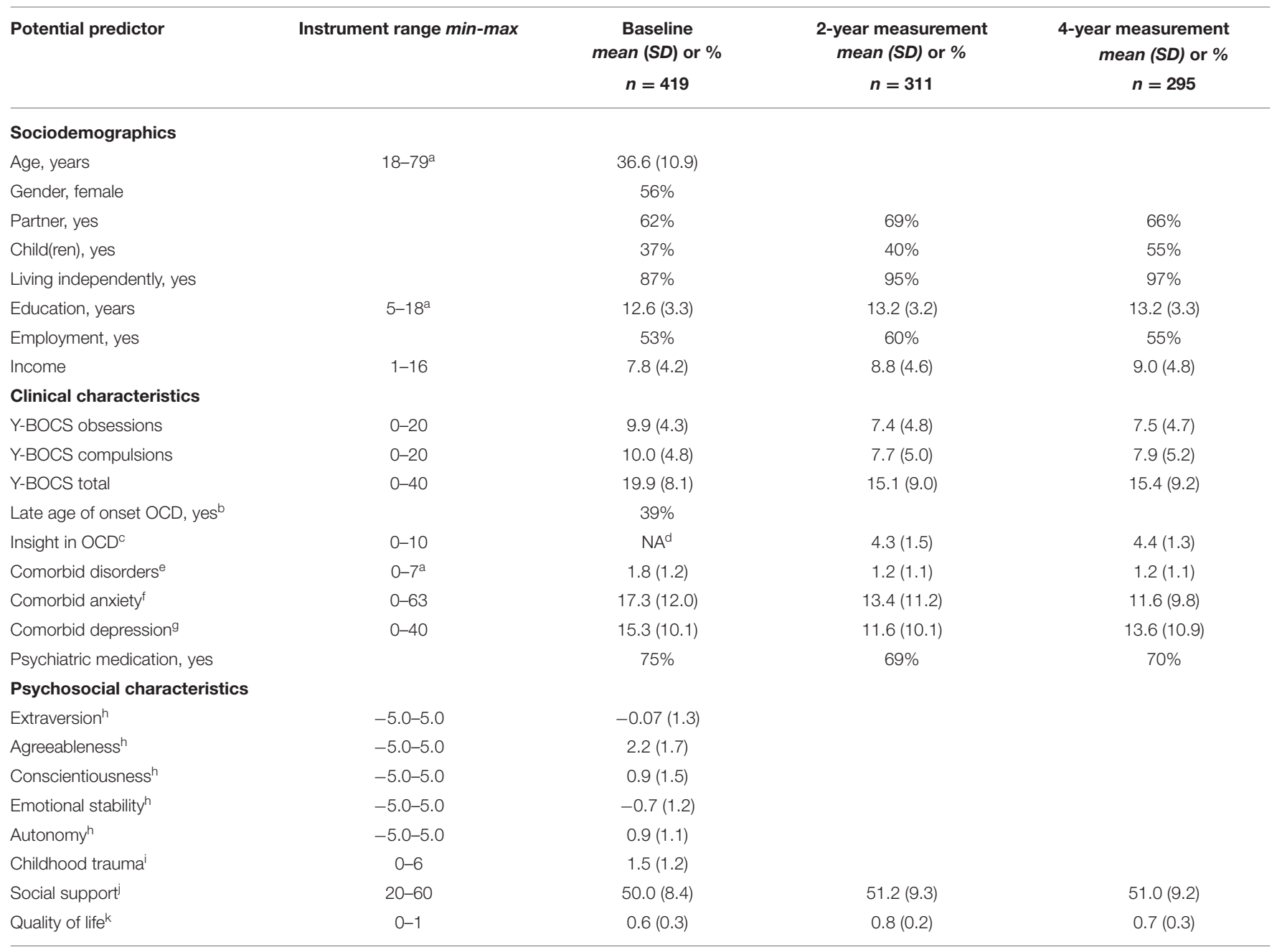

${ }^{a}$ Range in dataset.

${ }^{b}$ Onset $\geq 20$ years.

${ }^{c}$ Overvalued Ideas Scale.

${ }^{d}$ Not available.

${ }^{e}$ Number of current comorbid psychiatric disorders.

${ }^{f}$ Beck Anxiety Index.

${ }^{g}$ Beck Depression Inventory.

${ }^{h}$ Subscale of Five-Factor Personality Inventory (FFPl).

iStructured Trauma Interview.

iSocial Support Inventory.

${ }^{k} E Q-5 D$ utility score.

From the sensitivity analysis, in which we repeated the analyses but corrected for Y-BOCS severity, it appeared that the same predictors were significantly related to intensive treatment in the final multivariable analysis. Thus, these factors predict intensive treatment independently of OCD severity.

Insight in $\mathrm{OCD}$ was not significantly related to intensive treatment $[\mathrm{OR}=1.07,95 \% \mathrm{CI}(0.98,1.18) ; p=0.14]$.

\section{DISCUSSION}

We studied potential predictors of intensive treatment in the subsequent 2 years in patients with OCD over the course of
6 years. It appeared that patients with OCD who were single, who had more severe comorbid depressive symptoms, who used psychotropic medication, and who had a low quality of life were significantly more likely to have intensive treatment 2 years later. Our results on being single and more severe comorbid depression resemble the results concerning other mental disorders (18, $19,21)$. Thus, also in patients with OCD, these variables predict future intensive treatment. Quality of life as a potential predictor of intensive treatment has not been studied before. Our result that psychotropic medication predicts future intensive treatment is not congruent with previous research results in which a negative attitude toward medication-and thus likely not 
TABLE 2 | Treatment of patients with OCD over the course of 6 years.

\begin{tabular}{lcccc}
\hline Treatment & Baseline $^{\mathbf{a}}$ & 2-year & 4-yearb & 6-year \\
\hline Intensive treatment & & & & \\
Number of days & & & & \\
Mean (SD) & $55.8(46.4)$ & $96.3(103.3)$ & $168.9(183.5)$ & $78.7(143.3)$ \\
Median & 40 & 55 & 80 & 30 \\
$n$ & $105(25 \%)$ & $76(24 \%)$ & $40(14 \%)$ & $30(11 \%)$ \\
Outpatient treatment & & & & \\
Number of sessions & & & & \\
Mean (SD) & $10.2(8.7)$ & $30.1(29.0)$ & $24.9(26.6)$ & $23.2(22.0)$ \\
Median & 7 & 21 & 16 & 18 \\
$n$ & $287(68 \%)$ & $194(62 \%)$ & $166(56 \%)$ & $143(53 \%)$ \\
No treatment & & & & \\
$n$ & $26(6 \%)$ & $38(12 \%)$ & $88(30 \%)$ & $95(35 \%)$ \\
Missing & $1(0 \%)$ & $3(1 \%)$ & $1(0 \%)$ & $4(1 \%)$ \\
$n$ & 419 & 311 & 295 & 272 \\
\hline
\end{tabular}

a Treatment in the previous 6 months.

${ }^{b}$ Treatment in the previous 2 years.

using medication-predicted admission $(18,22)$. This difference might reflect the different study populations. While in patients with psychotic disorders or mood disorders medication has a large effect on symptoms and prevents relapse, crisis, and hospitalization $(45,46)$, in OCD, medication has only a moderate effect. SSRIs cause a mean reduction of 3.2 points on the Y-BOCS, over placebo, in patients with OCD according to a meta-analysis including 17 studies (3,097 participants) (47). Therefore, patients with OCD not taking medication usually does not lead to severe relapse or crisis, or an increase in the risk of hospitalization. A second explanation for our finding might be that stepped-care principles were followed in the treatment of OCD that indicate prescription of psychotropic medication before stepping up to more intensive treatments (3).

Contradictory to our hypotheses, the following potential predictors did not significantly predict intensive treatment. Remarkably, although severity of OCD was associated with intensive treatment in the univariable analysis of our study, this association disappeared in the multivariable models, indicating that other variables were more important in predicting intensive treatment. This might indicate that despair and limitations as a result of OCD are more important reasons for intensive treatment than severity of OCD per se. Next, insight in OCD did not predict intensive treatment in our study. This is not congruent with a previous finding in patients with several mental disorders that better insight was predictive of readmission (48). Also, it is not in line with previous findings that patients with poor insight in OCD were less likely to seek mental health care (49). In addition, poor insight in OCD was previously related to severity and chronicity of OCD (50-52). Possibly, effects of insight and help-seeking on intensive treatment cancel each other out. More specifically, patients with poor insight are often severe and chronic patients for whom intensive treatment is indicated. However, they are less likely to seek help. Conversely, patients with good insight do seek help but need intensive treatment less often. Lastly, childhood trauma was not predictive of intensive treatment in our study. To our knowledge, childhood trauma has not been studied as a potential predictor for intensive treatment before. Contradictory results have been found on the association between childhood trauma and severity and chronicity of OCD $(28-30,53)$. While childhood trauma is an important predictor of severity and chronicity of depression in patients with depressive disorders, the relationship between childhood trauma and severity and chronicity of OCD is less clear (54).

The predictors of intensive treatment that have emerged from our study might be used to tailor intensive treatment to the characteristics of the patients involved. For instance, single patients obviously lack the support from a partner, which might make it harder for them to stay motivated in the face of setbacks in treatment. Therapists may need to organize or offer extra support to pull these patients through. Next, patients with comorbid depressive symptoms or with a low quality of life may have difficulty following an intensive treatment program. In that case, adapting the treatment to the impairment of the patient may be helpful, and could be done by including activation in treatment or by shortening treatment days.

Our results indicate that intensive treatment might be prevented by improving comorbid depression and quality of life in first-step treatments in addition to treating OCD. In other words, to not focus only on diminishing OCD symptoms in treatment but also on vitality and promoting a fulfilling life with elements that patients want from life, like work, pleasurable activities, a partner, and a social network. We recommend therapists to encourage patients to fulfill life's wishes while allowing them to be hindered by OCD as little as possible. In our clinical experience, patients tend to postpone fulfilling their life's wishes based on the idea that it is better to wait until the OCD symptoms have disappeared. However, this conviction contributes to the notion of being disabled, which drives patients further away from their goals in life and in treatment. Therefore, therapists should educate patients about the importance of working on their life's goals in treatment in addition to working on OCD. Furthermore, therapists can help to find practical solutions to obstacles that may arise.

During the last decade, it has been accepted that recovery from mental disorders does not just entail having fewer symptoms but also regaining functioning and resuming a meaningful life (55). Guidelines like the NICE and the APA guidelines recognize the importance of focusing on functioning and quality of life in treatment $(3,4)$. Also, treatments are increasingly being evaluated using quality of life outcome measures (56-58). Moreover, recovery-oriented treatment programs have been implemented for patients with severe mental illness like schizophrenia, bipolar disorder, major depressive disorder, borderline personality disorder, and substance use disorders. These treatment programs foster adapting to chronic mental illness and movement toward personally meaningful goals like work and education (59-61). Recovery-oriented treatment programs help to improve both 
TABLE 3 | Results of logistic GEE analyses of potential predictors of intensive treatment 2 years later over a time-period of 6 years.

\begin{tabular}{|c|c|c|c|c|c|c|c|c|c|c|c|c|}
\hline & \multicolumn{3}{|c|}{ Univariable analyses } & \multicolumn{3}{|c|}{$\begin{array}{l}\text { Multivariable analyses } \\
\text { within categories }\end{array}$} & \multicolumn{3}{|c|}{$\begin{array}{c}\text { Multivariable analyses } \\
\text { over categories model } 1^{\mathrm{a}}\end{array}$} & \multicolumn{3}{|c|}{$\begin{array}{l}\text { Multivariable analyses } \\
\text { over categories model } 2^{b}\end{array}$} \\
\hline & OR & $95 \% \mathrm{Cl}$ & $p$ & OR & $95 \% \mathrm{Cl}$ & $p$ & OR & $95 \% \mathrm{Cl}$ & $p$ & OR & $95 \% \mathrm{Cl}$ & $p$ \\
\hline \multicolumn{13}{|l|}{ Sociodemographics } \\
\hline Age, years & 0.99 & $0.98,1.01$ & 0.30 & & & & & & & & & \\
\hline Gender, female & 1.17 & $0.83,1.65$ & 0.38 & & & & & & & & & \\
\hline Partner, yes & 0.54 & $0.44,0.68$ & $<0.01^{\star}$ & 0.57 & $0.45,0.71$ & $<0.01^{\star}$ & 0.62 & $0.51,0.76$ & $<0.01^{\star}$ & 0.62 & $0.49,0.77$ & $<0.01^{*}$ \\
\hline Child(ren), yes & 1.33 & $0.92,1.92$ & 0.12 & & & & & & & & & \\
\hline Living independently, yes & 0.51 & $0.31,0.84$ & $0.01^{*}$ & & & & & & & & & \\
\hline Education, years & 0.93 & $0.89,0.98$ & $0.01^{*}$ & & & & & & & & & \\
\hline Employment, yes & 0.44 & $0.30,0.64$ & $<0.01^{*}$ & 0.50 & $0.45,0.71$ & $<0.01^{\star}$ & & & & & & \\
\hline Income & 0.97 & $0.93,1.01$ & 0.12 & & & & & & & & & \\
\hline \multicolumn{13}{|l|}{ Clinical characteristics } \\
\hline Y-BOCS total & 1.10 & $1.06,1.14$ & $<0.01^{\star}$ & & & & & & & & & \\
\hline Late age of onset OCD, yes ${ }^{c}$ & 1.01 & $0.84,1.20$ & 0.95 & & & & & & & & & \\
\hline Comorbid disorders $^{\mathrm{d}}$ & 1.30 & $1.19,1.43$ & $<0.01^{*}$ & & & & & & & & & \\
\hline Comorbid anxietye & 1.04 & $1.02,1.05$ & $<0.01^{*}$ & & & & & & & & & \\
\hline Comorbid depression $^{f}$ & 1.05 & $1.04,1.06$ & $<0.01^{\star}$ & 1.05 & $1.04,1.06$ & $<0.01^{\star}$ & 1.04 & $1.03,1.05$ & $<0.01^{*}$ & & & \\
\hline Psychiatric medication, yes & 2.75 & $1.62,4.68$ & $<0.01^{\star}$ & 2.11 & $1.22,3.63$ & $0.01^{\star}$ & 2.02 & $1.17,3.48$ & $0.01^{*}$ & 2.16 & $1.25,3.74$ & $0.01^{*}$ \\
\hline \multicolumn{13}{|l|}{ Psychosocial characteristics } \\
\hline Extraversiong & 0.81 & $0.70,0.93$ & $<0.01^{*}$ & & & & & & & & & \\
\hline Agreeableness $^{g}$ & 0.96 & $0.80,1.16$ & 0.70 & & & & & & & & & \\
\hline Conscientiousness ${ }^{9}$ & 1.03 & $0.88,1.21$ & 0.74 & & & & & & & & & \\
\hline Emotional stability ${ }^{g}$ & 0.88 & $0.75,1.02$ & 0.10 & & & & & & & & & \\
\hline Autonomyg & 0.84 & $0.72,0.97$ & $0.02^{*}$ & & & & & & & & & \\
\hline Childhood trauma $^{\text {h }}$ & 1.14 & $0.99,1.30$ & 0.07 & & & & & & & & & \\
\hline Social support ${ }^{i}$ & 0.98 & $0.96,0.99$ & $0.01^{*}$ & & & & & & & & & \\
\hline Quality of lifej & 0.23 & $0.14,0.38$ & $<0.01^{\star}$ & 0.23 & $0.14,0.38$ & $<0.01^{*}$ & & & & 0.29 & $0.19,0.46$ & $<0.01^{*}$ \\
\hline
\end{tabular}

a Quality of life was omitted in model 1 due to multicollinearity between comorbid depression and quality of life.

${ }^{b}$ Comorbid depression was omitted in model 2 due to multicollinearity between comorbid depression and quality of life.

${ }^{c}$ Onset $\geq 20$ years.

${ }^{d}$ Number of current comorbid psychiatric disorders.

eBeck Anxiety Index.

${ }^{f}$ Beck Depression Inventory.

g Subscale of Five-Factor Personality Inventory (FFPI).

${ }^{\text {h }}$ Structured Trauma Interview.

iSocial Support Inventory.

${ }^{j} E Q-5 D$ utility score.

${ }^{*} p<0.05$.

symptoms and functioning and help reduce hospitalization in these patients with severe mental illness (59). Another treatment that can be effective in improving quality of life is acceptance and commitment therapy (ACT), which aims to accept negative feelings, while moving toward meaningful goals in accordance with personal values (62-64).

A limitation of this study is that although we had a longitudinal study design with potential predictors preceding the outcome measure (intensive treatment) in time, we were unable to establish causal connections between potential predictors and intensive treatment. Future research should thus examine whether treatment of the significantly associated predictors of our study indeed prevents intensive treatment. Another limitation is the attrition rate of $35 \%$ over the course of 6 years. To investigate whether dropout was selective, we have compared baseline characteristics of patients who participated in the 6-year assessment with patients who did not participate. Patients did not differ on any of the baseline characteristics except that patients who dropped out had less years of education (mean $=11.7$; $\mathrm{SD}=3.3$ ) compared to patients who participated in the 6-year assessment $[$ mean $=13.1 ; \mathrm{SD}=3.2$; $\left.t_{(416)}=-4.2, p<0.01\right]$. In previous studies, education was a determinant of attrition as well $(65,66)$. Presumably, our results were not biased by selective attrition. Last limitation is a potential historical effect due to the fact that the data was collected between 2005 and 2015. However, the intensive 
treatments that were common in the Netherlands during the NOCDA data collection have largely remained the same to date. This study also had a strength: we had access to a large, representative sample of treatment-seeking patients with OCD who were followed for a long period of time. Thus, our results are generalizable to clinically referred OCD patients in a specialized setting.

In conclusion, therapists should be aware that patients with OCD who are single, who have more severe comorbid depression, who use psychotropic medication, and who have a low quality of life or a drop in quality of life are at risk for intensive treatment. This is significant because knowledge of these predictors might help to optimize first-step treatments for patients with OCD to prevent the necessity of intensive treatment. In addition, the significant predictors of our study might be used to tailor intensive treatment to the characteristics of patients involved. We advise working on comorbid depression and personal goals in treatment in addition to working on OCD. Also, we advise providing extra support in treatment for patients who need it and to adjust treatment to impairments due to comorbid depressive symptoms or a low quality of life.

\section{DATA AVAILABILITY STATEMENT}

The datasets presented in this article are not readily available because of privacy restrictions. Requests to access the datasets should be directed to the authors and the datasets will be made available after a data analysis plan is approved and a data sharing form is filled out.

\section{REFERENCES}

1. Remmerswaal KCP, Batelaan NM, Hoogendoorn AW, van der Wee NJA, van Oppen P, van Balkom A. Four-year course of quality of life and obsessive-compulsive disorder. Soc Psychiatry Psychiatr Epidemiol. 55, 9891000. (2019). doi: 10.1007/s00127-019-01779-7

2. Lovell $\mathrm{K}$, Bee $\mathrm{P}$. Implementing the NICE OCD/BDD guidelines. Psychol Psychother. (2008) 81(Pt 4):365-76. doi: 10.1348/147608308X 320107

3. National Institute for Health and Care Excellence guidelines for mental health care. Obsessive compulsive disorder and body dysmorphic disorder: treatment, Clinical guideline [CG31] (2005). Available online at: https://www. nice.org.uk/guidance/cg3 (accessed March 22, 2021).

4. American Psychiatric Association. Practice Guideline for the Treatment of Patients With Obsessive-Compulsive Disorder. Arlington (2007).

5. van Balkom ALJM, van Vliet IM, Emmelkamp PMG, Bockting CLH, Spijker J, Hermens MLM, et al. Multidisciplinaire Richtlijn Angststoornissen (3e revisie, 2013). Utrecht: Trimbos-instituut (2013).

6. Meeuwissen JAC, Feenstra TL, Smit F, Blankers M, Spijker J, Bockting CLH, et al. The cost-utility of stepped-care algorithms according to depression guideline recommendations - results of a state-transition model analysis. $J$ Affect Disord. (2019) 242:244-54. doi: 10.1016/j.jad.2018.08.024

7. Falkenstein MJ, Nota JA, Krompinger JW, Schreck M, Garner LE, Potluri S, et al. Empirically-derived response trajectories of intensive residential treatment in obsessive-compulsive disorder: a growth mixture modeling approach. $J$ Affect Disord. (2019) 245:827-33. doi: 10.1016/j.jad.2018.11.075

\section{ETHICS STATEMENT}

The studies involving human participants were reviewed and approved by Medical Ethical Committee of the VU-University Medical Centre. The patients/participants provided their written informed consent to participate in this study.

\section{AUTHOR CONTRIBUTIONS}

JdM and KR designed the study, wrote the manuscript and performed the literature search. NB, AvB, and HV designed the study and supervised all aspects of this study. $\mathrm{PvO}$ organized the database and had significant input on the text. JT designed the study and performed the statistical analysis. All authors contributed to manuscript revision, read, and approved the submitted version.

\section{FUNDING}

The research infrastructure needed to complete the baseline measurements (including personnel and materials) has been financed almost exclusively by the participating organizations (Academic Department of Psychiatry, UMC/GGZ inGeest, Amsterdam, the Netherlands; Marina de Wolf Centre for Anxiety Research, Ermelo; Centre for Anxiety Disorders Overwaal, Lent; Dimence, GGZ Overijssel; Department of Psychiatry, Leiden University Medical Centre, Leiden; Mental Health Care Centre Noord- en Midden-Limburg, Venray; Academic Anxiety Centre, PsyQ Maastricht, Maastricht University, Division Mental Health and Neuroscience). The fieldwork coordinator was financed for 1 year by a research grant from the Stichting Steun.

8. Chase T, Wetterneck CT, Bartsch RA, Leonard RC, Riemann BC. Investigating treatment outcomes across OCD symptom dimensions in a clinical sample of OCD patients. Cogn Behav Ther. (2015) 44:36576. doi: 10.1080/16506073.2015.1015162

9. Siwiec SG, Riemann BC, Lee HJ. Predictors of acute outcomes for intensive residential treatment of obsessive-compulsive disorder. Clin Psychol Psychother. (2019) 26:661-72. doi: 10.1002/cpp.2389

10. Brennan BP, Lee C, Elias JA, Crosby JM, Mathes BM, Andre MC, et al. Intensive residential treatment for severe obsessive-compulsive disorder: characterizing treatment course and predictors of response. J Psychiatr Res. (2014) 56:98-105. doi: 10.1016/j.jpsychires.2014.05.008

11. Boschen MJ, Drummond LM, Pillay A. Treatment of severe, treatmentrefractory obsessive-compulsive disorder: a study of inpatient and community treatment. CNS Spectr. (2008) 13:1056-65. doi: 10.1017/S1092852900017119

12. Veale D, Naismith I, Miles S, Childs G, Ball J, Muccio F, et al. Outcome of intensive cognitive behaviour therapy in a residential setting for people with severe obsessive compulsive disorder: a large open case series. Behav Cogn Psychother. (2016) 44:331-46. doi: 10.1017/S1352465815000259

13. Taube-Schiff M, Rector NA, Larkin P, Mehak A, Richter MA. Effectiveness of intensive treatment services for obsessive compulsive disorder: outcomes from the first Canadian residential treatment program. Int J Psychiatry Clin Pract. (2020) 24:59-67. doi: 10.1080/13651501.2019.1676450

14. Hertenstein E, Thiel N, Herbst N, Freyer T, Nissen C, Kulz AK, et al. Quality of life changes following inpatient and outpatient treatment in obsessivecompulsive disorder: a study with 12 months follow-up. Ann Gen Psychiatry. (2013) 12:4. doi: 10.1186/1744-859X-12-4 
15. Stewart SE, Stack DE, Farrell C, Pauls DL, Jenike MA. Effectiveness of intensive residential treatment (IRT) for severe, refractory obsessive-compulsive disorder. J Psychiatr Res. (2005) 39:6039. doi: 10.1016/j.jpsychires.2005.01.004

16. Drummond LM. The treatment of severe, chronic, resistant obsessivecompulsive disorder. An evaluation of an in-patient programme using behavioural psychotherapy in combination with other treatments. $\mathrm{Br} J$ Psychiatry. (1993) 163:223-9. doi: 10.1192/bjp.163.2.223

17. Buchanan AW, Meng KS, Marks IM. What predicts improvement and compliance during the behavioral treatment of obsessive compulsive disorder? Anxiety. (1996) 2:22-7. doi: 10.1002/(SICI) 1522-7154(1996)2:1<22::AID-ANXI3>3.0.CO;2-F

18. Donisi V, Tedeschi F, Wahlbeck K, Haaramo P, Amaddeo F. Pre-discharge factors predicting readmissions of psychiatric patients: a systematic review of the literature. BMC Psychiatry. (2016) 16:449. doi: 10.1186/s12888-0161114-0

19. Tan J, Conlon C, Tsamparli A, O’Neill D, Adamis D. (2019). The association between family dysfunction and admission to an acute mental health inpatient unit: A prospective study. Ir J Psychol Med. 1-11. doi: 10.1017/ipm.2019.41

20. Alm S, Laftman SB, Sivertsson F, Bohman H. Poor family relationships in adolescence as a risk factor of in-patient psychiatric care across the life course: a prospective cohort study. Scand J Public Health. 48, 726-732. (2020). doi: 10.1177/1403494820902914

21. Han X, Jiang F, Tang Y, Needleman J, Guo M, Chen Y, et al. Factors associated with 30-day and 1-year readmission among psychiatric inpatients in Beijing China: a retrospective, medical record-based analysis. BMC Psychiatry. (2020) 20:113. doi: 10.1186/s12888-020-02515-1

22. Robinson DG, Schooler NR, Rosenheck RA, Lin H, Sint KJ, Marcy P, et al. Predictors of hospitalization of individuals with first-episode psychosis: data from a 2-year follow-up of the RAISE-ETP. Psychiatr Serv. (2019) 70:56977. doi: 10.1176/appi.ps.201800511

23. Wright ER, Gronfein WP, Owens TJ. Deinstitutionalization, social rejection, and the self-esteem of former mental patients. J Health Soc Behav. (2000) 41:68-90. doi: 10.2307/2676361

24. Loch AA. Discharged from a mental health admission ward: is it safe to go home? A review on the negative outcomes of psychiatric hospitalization. Psychol Res Behav Manag. (2014) 7:137-45. doi: 10.2147/PRBM.S35061

25. Fullana MA, Mataix-Cols D, Trujillo JL, Caseras X, Serrano F, Alonso P, et al. Personality characteristics in obsessive-compulsive disorder and individuals with subclinical obsessive-compulsive problems. Br J Clin Psychol. (2004) 43(Pt 4):387-98. doi: 10.1348/0144665042388937

26. Stavropoulos V, Moore KA, Lazaratou H, Dikaios D, Gomez R. A multilevel longitudinal study of obsessive compulsive symptoms in adolescence: male gender and emotional stability as protective factors. Ann Gen Psychiatry. (2017) 16:42. doi: 10.1186/s12991-017-0165-Z

27. Palardy V, El-Baalbaki G, Fredette C, Rizkallah E, Guay S. Social support and symptom severity among patients with obsessive-compulsive disorder or panic disorder with agoraphobia: a systematic review. Eur J Psychol. (2018) 14:254-86. doi: 10.5964/ejop.v14i1.1252

28. Tibi L, van Oppen P, van Balkom A, Eikelenboom M, Hendriks GJ, Anholt GE. Childhood trauma and attachment style predict the four-year course of obsessive compulsive disorder: findings from the Netherlands obsessive compulsive disorder study. J Affect Disord. (2020) 264:20614. doi: 10.1016/j.jad.2019.12.028

29. Semiz UB, Inanc L, Bezgin $\mathrm{CH}$. Are trauma and dissociation related to treatment resistance in patients with obsessivecompulsive disorder? Soc Psychiatry Psychiatr Epidemiol. (2014) 49:1287-96. doi: 10.1007/s00127-013-0787-7

30. Gothelf D, Aharonovsky O, Horesh N, Carty T, Apter A. Life events and personality factors in children and adolescents with obsessive-compulsive disorder and other anxiety disorders. Compr Psychiatry. (2004) 45:1928. doi: 10.1016/j.comppsych.2004.02.010

31. Schuurmans J, van Balkom AJ, van Megen HJ, Smit JH, Eikelenboom M, Cath DC, et al. The Netherlands Obsessive Compulsive Disorder Association (NOCDA) study: design and rationale of a longitudinal naturalistic study of the course of OCD and clinical characteristics of the sample at baseline. Int J Methods Psychiatr Res. (2012) 21:273-85. doi: 10.1002/mpr.1372
32. First MB, Spitzer RL, Gibbon M, Williams JBW. Structured Clinical Interview for DSM-IV Axis I Disorders - Patient Edition (Scid-I/P, Version 2.0). Lisse: Swets \& Zeitlinger (1999).

33. Bouwmans C, De Jong K, Timman R, Zijlstra-Vlasveld M, Van der Feltz-Cornelis C, Tan Swan S, et al. Feasibility, reliability and validity of a questionnaire on healthcare consumption and productivity loss in patients with a psychiatric disorder (TiC-P). BMC Health Serv Res. (2013) 13:217. doi: 10.1186/1472-6963-13-217

34. Goodman WK, Price LH, Rasmussen SA, Mazure C, Delgado P, Heninger GR, et al. The Yale-Brown obsessive compulsive scale. II. Validity. Arch Gen Psychiatry. (1989) 46:1012-6. doi: 10.1001/archpsyc.1989.01810110 054008

35. Goodman WK, Price LH, Rasmussen SA, Mazure C, Fleischmann RL, Hill CL, et al. The Yale-Brown obsessive compulsive scale. I. Development, use, and reliability. Arch Gen Psychiatry. (1989) 46:100611. doi: 10.1001/archpsyc.1989.01810110048007

36. Beck AT, Epstein N, Brown G, Steer RA. An inventory for measuring clinical anxiety: psychometric properties. J Consult Clin Psychol. (1988) 56:8937. doi: 10.1037/0022-006X.56.6.893

37. Beck AT, Steer RA, Ball R, Ciervo CA, Kabat M. Use of the beck anxiety and depression inventories for primary care with medical outpatients. Assessment. (1997) 4:211-9. doi: 10.1177/107319119700400301

38. Beck AT, Steer RA, Garbin MG. Psychometric properties of the Beck Depression Inventory "25 Years of Evaluation". Clin Psychol Rev. (1988) 8:77-100. doi: 10.1016/0272-7358(88)90050-5

39. Furlanetto LM, Mendlowicz MV, Romildo Bueno J. The validity of the Beck Depression Inventory-Short Form as a screening and diagnostic instrument for moderate and severe depression in medical inpatients. J Affect Disord. (2005) 86:87-91. doi: 10.1016/j.jad.2004.12.011

40. Neziroglu F, McKay D, Yaryura-Tobias JA, Stevens KP, Todaro J. The Overvalued Ideas Scale: development, reliability and validity in obsessive-compulsive disorder. Behav Res Ther. (1999) 37:881-902. doi: 10.1016/S0005-7967(98)00191-0

41. Draijer N. Gestructureerd Trauma Interview (Structured Trauma Interview; STI). Amsterdam: Department of Psychiatry; Vrije University (1989).

42. Hendriks AAJ, Hofstee WKB, de Raad B. The five-factor personality inventory (FFPI). Personality Individ Differ. (1999) 27:307-25. doi: 10.1016/S0191-8869(98)00245-1

43. Brown SD, Brady T, Lent RW, Wolfert J, Hall S. Perceived social support among college students: three studies of the psychometric characteristics and counseling uses of the social support inventory. J Counsel Psychol. (1987) 34:337-54. doi: 10.1037/0022-0167.34.3.337

44. EuroQol Group. EuroQol-a new facility for the measurement of health-related quality of life. Health Policy. (1990) 16:199208. doi: 10.1016/0168-8510(90)90421-9

45. Leucht S, Tardy M, Komossa K, Heres S, Kissling W, Salanti G, et al. Antipsychotic drugs versus placebo for relapse prevention in schizophrenia: a systematic review and meta-analysis. Lancet. (2012) 379:2063-71. doi: 10.1016/S0140-6736(12)60239-6

46. Kishi T, Ikuta T, Matsuda Y, et al. Mood stabilizers and/or antipsychotics for bipolar disorder in the maintenance phase: a systematic review and network meta-analysis of randomized controlled trials. Mol Psychiatry. (2020). doi: 10.1038/s41380-020-00946-6. [Epub ahead of print].

47. Soomro GM, Altman D, Rajagopal S, Oakley-Browne M. Selective serotonin re-uptake inhibitors (SSRIs) versus placebo for obsessive compulsive disorder (OCD). Cochrane Database Syst Rev. (2008) CD001765. doi: 10.1002/14651858.CD001765.pub3

48. Russo J, Roy-Byrne P, Jaffe C, Ries R, Dagadakis C, Avery D. Psychiatric status, quality of life, and level of care as predictors of outcomes of acute inpatient treatment. Psychiatr Serv. (1997) 48:1427-34. doi: 10.1176/ps.48.11. 1427

49. Besiroglu L, CIlli AS, Askin R. The predictors of health care seeking behavior in obsessive-compulsive disorder. Compr Psychiatry. (2004) 45:99108. doi: 10.1016/j.comppsych.2003.12.010

50. Jacob ML, Larson MJ, Storch EA. Insight in adults with obsessive-compulsive disorder. Compr Psychiatry. (2014) 55:896903. doi: 10.1016/j.comppsych.2013.12.016 
51. Bellino S, Patria L, Ziero S, Bogetto F. Clinical picture of obsessive-compulsive disorder with poor insight: a regression model. Psychiatry Res. (2005) 136:22331. doi: 10.1016/j.psychres.2004.04.015

52. Visser H, van Megen H, van Oppen P, Hoogendoorn A, Glas G, Neziroglu F, et al. The impact of poor insight on the course of Obsessive-Compulsive Disorder in patients receiving naturalistic treatment. J Obsessive Compulsive Relat Disord. (2017) 13:42-8. doi: 10.1016/j.jocrd.2017.03.003

53. Visser HA, van Minnen A, van Megen H, Eikelenboom M, Hoogendoorn AW, Kaarsemaker $\mathrm{M}$, et al. The relationship between adverse childhood experiences and symptom severity, chronicity, and comorbidity in patients with obsessive-compulsive disorder. J Clin Psychiatry. (2014) 75:10349. doi: 10.4088/JCP.13m08825

54. Nelson J, Klumparendt A, Doebler P, Ehring T. Childhood maltreatment and characteristics of adult depression: meta-analysis. Br J Psychiatry. (2017) 210:96-104. doi: 10.1192/bjp.bp.115.180752

55. Boardman J. Routine outcome measurement: recovery, quality of life and co-production. Br J Psychiatry. (2018) 212:4-5. doi: 10.1192/bjp.2017.5

56. Asnaani A, Kaczkurkin AN, Alpert E, McLean CP, Simpson HB, Foa EB. The effect of treatment on quality of life and functioning in OCD. Compr Psychiatry. (2017) 73:7-14. doi: 10.1016/j.comppsych.2016.10.004

57. Motivala SJ, Arellano M, Greco RL, Aitken D, Hutcheson N, Tadayonnejad $\mathrm{R}$, et al. Relationships between obsessive-compulsive disorder, depression and functioning before and after exposure and response prevention therapy. Int $J$ Psychiatry Clin Pract. (2018) 22:40-6. doi: 10.1080/13651501.2017.1351991

58. Winter L, Saryyeva A, Schwabe K, Heissler HE, Runge J, Alam M, et al. Longterm deep brain stimulation in treatment-resistant obsessive-compulsive disorder: outcome and quality of life at four to eight years follow-up. Neuromodulation. 24, 324-330. (2021). doi: 10.1111/ner.13232

59. White C, Frimpong E, Huz S, Ronsani A, Radigan M. Effects of the personalized recovery oriented services (PROS) program on hospitalizations. Psychiatr Q. (2018) 89:261-71. doi: 10.1007/s11126-017-9531-x

60. Bonnin CDM, Reinares M, Martinez-Aran A, Jimenez E, Sanchez-Moreno J, Sole B, et al. Improving functioning, quality of life, and well-being in patients with bipolar disorder. Int J Neuropsychopharmacol. (2019) 22:46777. doi: 10.1093/ijnp/pyz018
61. Burchi E, Hollander E, Pallanti S. From treatment response to recovery: a realistic goal in OCD. Int J Neuropsychopharmacol. (2018) 21:100713. doi: 10.1093/ijnp/pyy079

62. Twohig MP, Hayes SC, Plumb JC, Pruitt LD, Collins AB, Hazlett-Stevens H, et al. A randomized clinical trial of acceptance and commitment therapy versus progressive relaxation training for obsessive-compulsive disorder. J Consult Clin Psychol. (2010) 78:705-16. doi: 10.1037/a0020508

63. Arch JJ, Eifert GH, Davies C, Plumb Vilardaga JC, Rose RD, Craske MG. Randomized clinical trial of cognitive behavioral therapy (CBT) versus acceptance and commitment therapy (ACT) for mixed anxiety disorders. $J$ Consult Clin Psychol. (2012) 80:750-65. doi: 10.1037/a0028310

64. A-Tjak JG, Davis ML, Morina N, Powers MB, Smits JA, Emmelkamp PM. A meta-analysis of the efficacy of acceptance and commitment therapy for clinically relevant mental and physical health problems. Psychother Psychosom. (2015) 84:30-6. doi: 10.1159/000365764

65. Lamers F, Hoogendoorn AW, Smit JH, van Dyck R, Zitman FG, Nolen WA, et al. Sociodemographic and psychiatric determinants of attrition in the Netherlands Study of Depression and Anxiety (NESDA). Compr Psychiatry. (2012) 53:63-70. doi: 10.1016/j.comppsych.2011.01.011

66. de Graaf R, Bijl RV, Smit F, Ravelli A, Vollebergh WA. Psychiatric and sociodemographic predictors of attrition in a longitudinal study: the Netherlands Mental Health Survey and Incidence Study (NEMESIS). Am J Epidemiol. (2000) 152:1039-47. doi: 10.1093/aje/152.11.1039

Conflict of Interest: The authors declare that the research was conducted in the absence of any commercial or financial relationships that could be construed as a potential conflict of interest.

Copyright (c) 2021 du Mortier, Remmerswaal, Batelaan, Visser, Twisk, van Oppen and van Balkom. This is an open-access article distributed under the terms of the Creative Commons Attribution License (CC BY). The use, distribution or reproduction in other forums is permitted, provided the original author(s) and the copyright owner(s) are credited and that the original publication in this journal is cited, in accordance with accepted academic practice. No use, distribution or reproduction is permitted which does not comply with these terms. 